\title{
Liver resection versus liver transplantation for hepatocellular carcinoma within Milan criteria: a meta-analysis of 18,421 patients
}

\author{
Jin Hean Koh ${ }^{1 \#}$, Darren Jun Hao Tan ${ }^{1 \#}$, Yuki Ong ${ }^{1}$, Wen Hui Lim ${ }^{1}$, Cheng Han Ng${ }^{1}$, Phoebe Wen Lin Tay ${ }^{1}$, \\ Jie Ning Yong ${ }^{1}$, Mark D. Muthiah ${ }^{1,2,3}$, Eunice X. Tan ${ }^{1,2,3}$, Ning Qi Pang ${ }^{3,4}$, Beom Kyung Kim ${ }^{5,6}$, \\ Nicholas Syn ${ }^{1,7}$, Alfred Kow ${ }^{3,4}$, Brian K. P. Goh ${ }^{8,9}$, Daniel Q. Huang ${ }^{1,2,3}$
}

${ }^{1}$ Yong Loo Lin School of Medicine, National University of Singapore, Singapore, Singapore; 'Division of Gastroenterology and Hepatology, Department of Medicine, National University Hospital, Singapore, Singapore; ${ }^{3}$ National University Centre for Organ Transplantation, National University Health System, Singapore, Singapore; ${ }^{4}$ Division of Hepatobiliary \& Pancreatic Surgery, Department of Surgery, National University Hospital, Singapore, Singapore; ${ }^{5}$ Department of Internal Medicine, Yonsei University College of Medicine, Seoul, Republic of Korea; ${ }^{6}$ Yonsei Liver Center, Severance Hospital, Yonsei University Health System, Seoul, Republic of Korea; ${ }^{7}$ Biostatistics and Modelling Domain, Saw Swee Hock School of Public Health, National University of Singapore and National University Health System, Singapore, Singapore; ${ }^{8}$ Department of HepatoPancreato-Biliary and Transplant Surgery, Division of Surgery, Singapore General Hospital, Singapore, Singapore; ${ }^{9}$ Liver Transplant Service, SingHealth Duke-NUS Transplant Centre, Singapore, Singapore

Contributions: (I) Conception and design: DQ Huang, CH Ng, MD Muthiah; (II) Administrative support: MD Muthiah, DQ Huang; (III) Provision of study materials or patients: All authors; (IV) Collection and assembly of data: All authors; (V) Data analysis and interpretation: All authors; (VI) Manuscript writing: All authors; (VII) Final approval of manuscript: All authors.

\#These authors contributed equally to this work.

Correspondence to: Dr. Daniel Q. Huang, MBBS (S'pore), MRCP (UK), MMED (S'pore). Consultant Gastroenterologist and Hepatologist, Division of Gastroenterology and Hepatology, Department of Medicine, National University Hospital, Singapore, Singapore. Email: daniel_huang@nus.edu.sg; Darren Jun Hao Tan. Yong Loo Lin School of Medicine, National University of Singapore, Singapore, Singapore. Email: darrentan.j.h@gmail.com.

Background: Outcomes after liver resection (LR) and liver transplantation (LT) for hepatocellular carcinoma (HCC) are heterogenous and may vary by region, over time periods and disease burden. We aimed to compare overall survival (OS) and disease-free survival (DFS) between LT versus LR for HCC within the Milan criteria.

Methods: Two authors independently searched Medline and Embase databases for studies comparing survival after LT and LR for patients with HCC meeting the Milan criteria. Meta-analyses and metaregression were conducted using random-effects models.

Results: We screened 2,278 studies and included 35 studies with 18,421 patients. LR was associated with poorer OS [hazard ratio $(\mathrm{HR})=1.44 ; 95 \%$ confidence interval $(\mathrm{CI}): 1.14-1.81 ; \mathrm{P}<0.01$ ] and $\mathrm{DFS}(\mathrm{HR}=2.71$; 95\% CI: 2.23-3.28; $\mathrm{P}<0.01)$ compared to LT, with similar findings among intention-to-treat (ITT) studies. In uninodular disease, OS in LR was comparable to LT $(\mathrm{P}=0.13)$ but DFS remained poorer $(\mathrm{HR}=2.95$; $95 \% \mathrm{CI}$ : 2.30-3.79; $\mathrm{P}<0.01)$. By region, LR had poorer OS versus LT in North America and Europe $(\mathrm{P} \leq 0.01)$, but not Asia $(\mathrm{P}=0.25)$. LR had inferior survival versus LT in studies completed before 2010 ( $\mathrm{P}=0.01)$, but not after 2010 $(\mathrm{P}=0.12)$. Cohorts that underwent enhanced surveillance had comparable OS after LT and LR $(\mathrm{P}=0.33)$, but cohorts undergoing usual surveillance had worse OS after LR (HR =1.95; 95\% CI: 1.24-3.07; $\mathrm{P}<0.01)$.

Conclusions: Mortality after LR for HCC is nearly 50\% higher compared to LT. Survival between LR and LT were similar in uninodular disease. The risk of recurrence after LR is threefold that of LT.

Keywords: Hepatocellular carcinoma (HCC); liver resection (LR); liver transplant; survival; recurrence

Submitted Aug 23, 2021. Accepted for publication Nov 09, 2021.

doi: $10.21037 / \mathrm{hbsn}-21-350$

View this article at: https://dx.doi.org/10.21037/hbsn-21-350

^ ORCID: 0000-0002-5165-5061. 


\section{Introduction}

Hepatocellular carcinoma (HCC) is the third leading cause of cancer-related deaths globally (1-3). Liver transplantation (LT) and liver resection (LR) are first line options for curative treatment of HCC (4-6). LT treats both the tumour and the surrounding cirrhotic microenvironment $(7,8)$. It is associated with excellent long-term survival outcomes (9-11). Unfortunately, the availability of LT is hampered by the severe shortage of liver allografts (12). In contrast, LR is widely available, eliminates the need for an allograft but has a higher recurrence rate compared to LT (13).

Major society guidelines recommend LR when the hepatic function is preserved and sufficient remnant liver volume is maintained (4-6). By contrast, LT can be performed in the setting of hepatic decompensation and is recommended for patients with HCC within the Milan criteria, defined as 1 tumour up to $5 \mathrm{~cm}$, or up to 3 tumours not exceeding $3 \mathrm{~cm}$ in the absence of macrovascular invasion $(14,15)$.

No randomized controlled trial has been conducted to compare survival outcomes between patients receiving LT and LR for HCC. Previous analyses have been limited to results from observational studies $(13,16)$. A previous metaanalysis reported similar overall survival (OS) between LT and LR among patients meeting the Milan criteria, however, there were limited data available at the point of analysis (13). In addition, survival outcomes between LR and LT may have changed over time with the widespread availability of safe and efficacious antiviral therapies for both hepatitis $\mathrm{B}$ virus (HBV) and hepatitis $\mathrm{C}$ virus (HCV) $(17,18)$. Furthermore, it is unclear how survival outcomes vary by region, surveillance strategy and disease burden.

Therefore, through a systematic review and metaanalytic approach, we aimed to compare the OS and disease-free survival (DFS) of LR versus LT for treatment of patients with HCC within the Milan criteria. Our secondary aims were to compare the survival outcomes between LT and LR by region, time period, surveillance strategy and the presence of uninodular disease. We present the following article in accordance with the PRISMA reporting checklist (available at https://hbsn.amegroups. com/article/view/10.21037/hbsn-21-350/rc).

\section{Methods}

\section{Search strategy}

This review was registered with PROSPERO
(CRD42021255085). With reference to the Preferred Reporting Items for Systematic Review and Meta-Analyses (PRISMA) guidelines (19), a search was conducted on Medline and Embase databases for articles relating to LT and LR for the treatment of HCC from inception to 8 March 2021. The search strategy used was for 'liver transplantation', 'liver resection', and 'hepatocellular carcinoma' and the related terms in titles and abstracts. The full search strategy is included in Appendix 1. The references of included articles were also screened manually for a comprehensive search.

\section{Study selection}

Three authors (JHK, YO, WHL) independently screened abstracts to check the eligibility for inclusion, with disputes being resolved through consensus from a fourth independent author (DJHT). Retrospective and prospective cohort studies, cross-sectional studies and randomized controlled trials were considered for inclusion. Systematic reviews, meta-analyses, and editorials were excluded. Only English language articles were considered for inclusion. Studies were included if they (I) involved patients undergoing either LT or LR for HCC, (II) compared the survival outcomes, including OS and/or DFS, of LT and LR and (III) only included patients with tumours within the Milan criteria. Paediatric patients were excluded from the analysis.

\section{Data extraction}

Relevant data from included articles were extracted by a pair of independent authors (JHK and YO) into a structured proforma. The primary outcome of interest was the OS and DFS following LT or LR. OS was defined as the date of LT or LR to the date of death or last follow-up. DFS was defined as the time from LT or LR to the time of cancer recurrence or last follow-up. We extracted adjusted hazard ratio (HR) where possible. Study characteristics including author, year of study end-date, country, region, income level, and patient demographics [including but not limited to sample size, age, gender, MELD score, ChildPugh score, presence of microvascular invasion, presence of cirrhosis, alpha-fetoprotein (AFP) level, type of surveillance strategy, indication for transplant, presence of poorly differentiated tumour histology, number of tumour nodules, length of follow-up, and tumour size] were also extracted. Income levels were defined according to the definitions set 
by the World Bank (20). Tumour grade was evaluated via the Edmondson-Steiner classification.

Surveillance strategy was classified into enhanced and non-enhanced groups, with enhanced surveillance defined as computed tomography (CT) or magnetic resonance imaging (MRI), at 3 to 4 monthly intervals in the first 2 years after surgery, then imaging at least 6 monthly afterwards. Non-enhanced surveillance was defined as the use of CT or MRI less frequently than every 3 to 4 months within the first and second year postoperatively, imaging less frequently than 6 monthly from the third postoperative year onward, or the use of ultrasound rather than CT or MRI in the first two postoperative years.

\section{Statistical analysis and quality assessment}

All analysis was conducted in R Studio (Version 4.0.3) using the meta package. A conventional pairwise meta-analysis was done in HR using the DerSimonian and Laird random effects model to assess the comparative survival between LR and LT for HCC in terms of OS and DFS. Statistical heterogeneity was assessed via $\mathrm{I}^{2}$ and Cochran $\mathrm{Q}$ test values, where an $\mathrm{I}^{2}$ value of $25 \%, 50 \%$ and $75 \%$ represented low, moderate, and high degree of heterogeneity respectively $(21,22)$. A Cochran $Q$ test with $P$ value of $\leq 0.10$ was considered significant for heterogeneity. However, random effects models were used in all analysis regardless of heterogeneity as recent evidence suggests that it provides more robust outcome measures compared to the alternative fixed effects models (23). When sufficient studies were available, the effect of risk factors on the dependant variable, HR for OS and DFS between LR and LT, was determined via meta-regression. This was done via univariate metaregression using a mixed model with a logit transformation on independent variables including microinvasion, cirrhosis, Child-Pugh class, aetiology and poorly differentiated tumour histology. Statistical significance was considered for outcomes with a $\mathrm{P}$ value $\leq 0.05$. Subgroup analysis was considered for differing survival outcomes between LT and LR by type of postoperative surveillance strategy, region, income level, and time period (study end-date before and after year of 2010). Additionally, sensitivity analysis was conducted for studies that conducted intention-to-treat (ITT) analysis, which was defined as analysis of all patients who were listed for LT, including those who did not receive LT due to dropout from the waiting list from death or progression of HCC. Sensitivity analysis was also conducted for studies involving living donor liver transplantation
(LDLT) patients only. Quality assessment of included articles was done with the Newcastle-Ottawa Scale quality assessment (NOS). The NOS rates the risk of bias of cohort studies on the premises of appropriateness of sample frame, sampling method, ascertainment of exposure, demonstration that outcome of interest was not present at start of study, comparability of cohorts, methods for assessment of outcomes, duration of follow-up and adequacy of follow-up (24). Publication bias was assessed by visual inspection of the respective funnel plots (25).

\section{Results}

\section{Study selection and study characteristics}

A total of 2,278 articles were included in the initial search after removal of duplicates, of which 138 were selected for full text review; 35 articles met the final inclusion criteria (Figure 1), with 8 studies from China (26-33), 7 from the United States (34-40), 5 from South Korea (41-45), 2 each from France $(46,47)$, Germany $(48,49)$, Japan $(50,51)$ and Spain (52,53), 1 each from Canada (54), Italy (55), Hong Kong (56), Israel (57), Taiwan (58), Turkey (59), and 1 multicentre study (60). Tables S1,S2 contain the summary of the key characteristics and quality assessment for included articles. A total of 18,095 patients with tumours within the Milan criteria were included in our analysis, with 8,204 and 9,891 patients undergoing LT and LR respectively. The majority of articles were retrospective studies $(n=34)$, except for 1 prospective study; 11 articles provided survival data for uninodular HCC $(26,30-32,34,43,45,46,53,56,60)$; 20 articles had a study end-date before 2010 (33,35-37,40,42,43,45,47,49-56,60-62). Additionally, 14 studies used enhanced surveillance strategies for HCC surveillance after surgery $(26,28,30,33-35,40,43,44,56-58,61,62)$. All included studies were of high quality by NOS, with 10 studies having an NOS score of 9 , and 25 studies having an NOS score of 8 .

\section{Patient and tumour characteristics}

A summary of the baseline demographics and tumour characteristics in the LT and LR groups is presented in Table 1. There was no significant difference in patient demographics or tumour characteristics between LT and LR, except for the presence of cirrhosis [LT: $95.51 \%$; $95 \%$ confidence interval (CI): 94.52-96.32 vs. LR: $87.19 \%$; 95\% CI: 85.97-88.31; P<0.001]. Mean age was 53.74 (95\% 


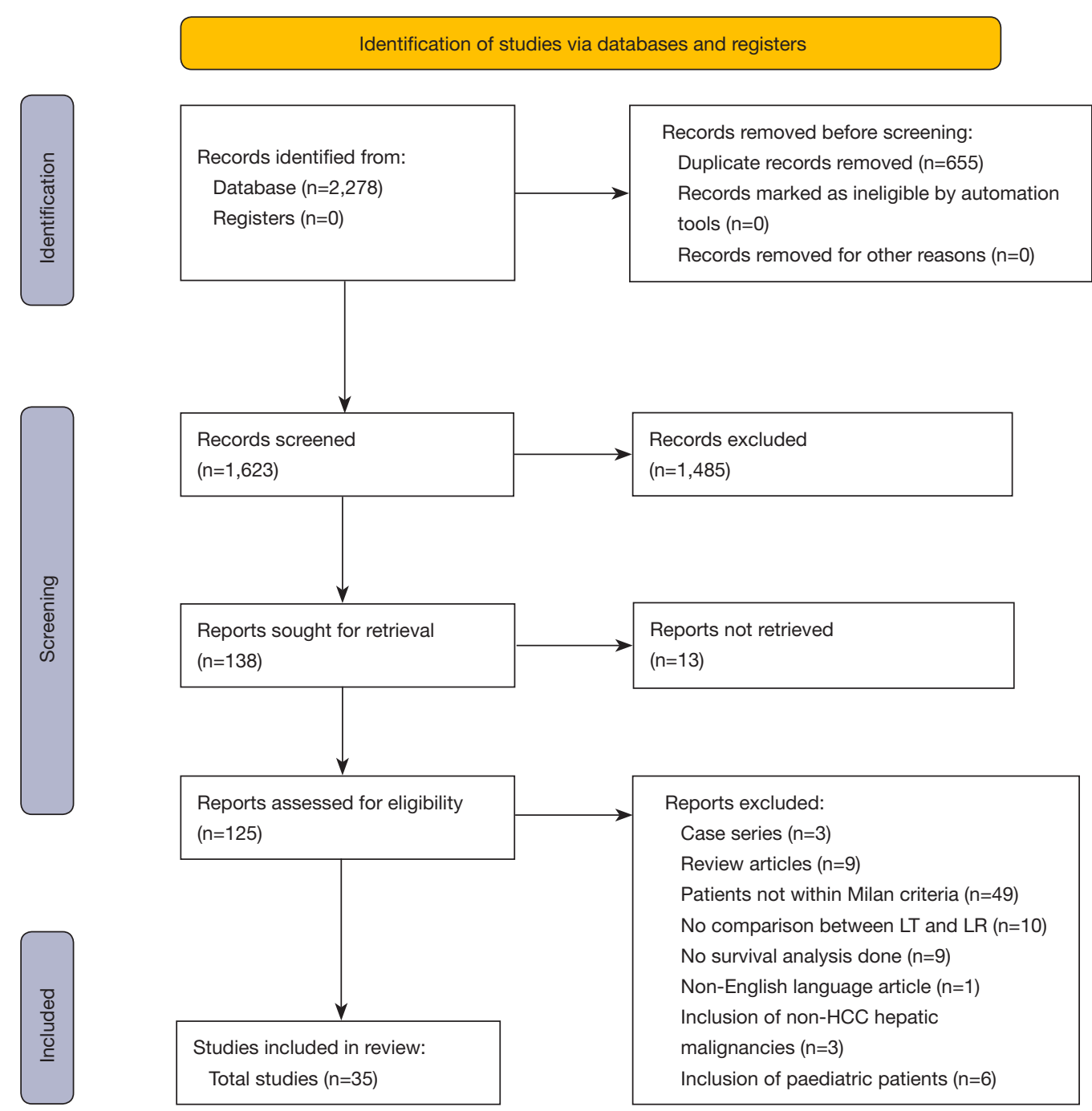

Figure 1 PRISMA flow diagram for included articles. LT, liver transplantation; LR, liver resection; HCC, hepatocellular carcinoma; PRISMA, Preferred Reporting Items for Systematic Review and Meta-Analyses.

CI: 51.59-55.90) years in the LT group, compared to 57.05 (95\% CI: $54.47-59.63$ ) years in the LR group $(\mathrm{P}=0.054)$. In both LT and LR groups, the most common etiology of liver disease was HBV infection (LT: $39.45 \%$; 95\% CI: $16.42-68$ vs. LR 47.67\%; 95\% CI: 27.57-68.56; $\mathrm{P}=0.658$ ), followed by HCV (LT: $33.56 \% ; 95 \%$ CI: 18.37-53.15 vs. LR: $19.79 \%$; $95 \%$ CI: $11.10-32.76$; $\mathrm{P}=0.184$. Alcoholic liver disease was the next most common etiology (LT: $13.52 \%$; 95\% CI: 6.21-26.95 vs. LR: 14.83\%; 95\% CI: 7.83-26.28; $\mathrm{P}=0.851$ ), followed by non-alcoholic steatohepatitis (NASH) (LT: 5.60\%; 95\% CI: 3.13-9.80 vs. LR: $9.22 \%$; 95\% CI: 5.59-14.85; $\mathrm{P}=0.1923)$.

With regards to tumour characteristics, $11.77 \%(95 \%$
CI: 8.39-16.26) of tumours in the LT group had poorly differentiated histology, compared to $14.84 \%$ (95\% CI: 8.90-23.71) in patients that underwent $L R(P=0.447)$. The proportion of patients with microvascular invasion (LT: 15.23\%; 95\% CI: 9.04-24.53 vs. LR: $19.83 \%$; $95 \%$ CI: 12.63-29.75; $\mathrm{P}=0.434$ ) and uninodular HCC (LT: $89.67 \%$; 95\% CI: 88.25-90.94 vs. LR: 91.15\%; 95\% CI: 90.09-92.11; $\mathrm{P}=0.080$ ) were also similar between patients that underwent LT and LR. Mean size of the largest lesion was 2.74 (95\% CI: 2.40-3.08) $\mathrm{cm}$ in patients that had undergone LT, compared to 3.24 (95\% CI: $2.79-3.68) \mathrm{cm}$ in the LR group ( $\mathrm{P}=0.084)$.

Among LT recipients, $78.07 \%$ (95\% CI: 75.88-80.11\%) of patients underwent LDLT, while 19.89\% (95\% CI: $17.93-$ 
Table 1 Patient demographics and tumour characteristics, by treatment

\begin{tabular}{|c|c|c|c|c|c|}
\hline Characteristics & $\begin{array}{l}\text { Number of studies } \\
\text { (total sample size) }\end{array}$ & LT (95\% Cl) & $\begin{array}{l}\text { Number of studies } \\
\text { (total sample size) }\end{array}$ & LR $(95 \% \mathrm{Cl})$ & $P$ \\
\hline Male (\%) & $23(2,344)$ & 81.13 (76.83-84.79) & $23(3,656)$ & $75.30(69.43-80.36)$ & 0.086 \\
\hline Age (years) & $23(2,386)$ & $53.74(51.59-55.90)$ & $24(3,676)$ & 57.05 (54.47-59.63) & 0.054 \\
\hline Cirrhosis (\%) & $21(2,047)$ & 95.51 (94.52-96.32) & $22(3,145)$ & $87.19(85.97-88.31)$ & $<0.001$ \\
\hline HCV (\%) & $17(1,991)$ & $33.56(18.37-53.15)$ & $18(2,993)$ & $19.79(11.10-32.76)$ & 0.184 \\
\hline ALD (\%) & $12(1,279)$ & 13.52 (6.21-26.95) & $12(435)$ & $14.83(7.83-26.28)$ & 0.851 \\
\hline NASH (\%) & $7(808)$ & $5.60(3.13-9.80)$ & $7(1,024)$ & $9.22(5.59-14.85)$ & 0.193 \\
\hline Tumour size $(\mathrm{cm})$ & $17(1,256)$ & $2.74(2.40-3.08)$ & $17(1,658)$ & $3.24(2.79-3.68)$ & 0.084 \\
\hline Uninodular HCC (\%) & $17(2,029)$ & 89.67 (88.25-90.94) & $17(3,073)$ & $91.15(90.09-92.11)$ & 0.08 \\
\hline LDLT (\%) & $16(1,336)$ & 78.07 (75.88-80.11) & - & - & - \\
\hline Asian centres & $12(923)$ & 96.97 (92.38-99.97) & - & - & - \\
\hline Non-Asian centres & $4(413)$ & $46.06(41.91-50.26)$ & - & - & - \\
\hline DDLT (\%) & $11(746)$ & 19.89 (17.93-22.01) & - & - & - \\
\hline
\end{tabular}

LT, liver transplantation; LR, liver resection; Cl, confidence interval; HBV, hepatitis B virus; HCV, hepatitis C virus; ALD, alcoholic liver disease; NASH, non-alcoholic steatohepatitis; HCC, hepatocellular carcinoma; LDLT, living donor liver transplantation; DDLT, deceased donor liver transplantation.

$22.01 \%)$ underwent deceased donor liver transplantation (DDLT). However, in Asian transplant centres, LDLT was the dominant mode of LT (96.97\%; 95\% CI: 92.38-99.97\%). Comparatively, in non-Asian transplant centres, there was a similar proportion of patients that underwent LDLT (46.06\%; 95\% CI: 41.91-50.26\%) and DDLT (48.44\%; $95 \%$ CI: $44.27-52.64 \%)$.

\section{OS}

\section{Overall and by time period}

A summary of the results is found in Table 2. From pooled analysis of 33 studies including 14,513 patients, patients that underwent LR had poorer OS compared to LT (HR =1.44; 95\% CI: 1.14-1.81; $\mathrm{P}<0.01$; Figure 2$)$. When results were stratified by date of study, LR was associated with significantly poorer OS compared to LT for studies completed before 2010 (HR =1.50, 95\% CI: 1.19-1.91; $\mathrm{P}<0.01)$. However, among studies that were completed in 2010 and after, there was no significant difference in OS (HR =1.39; 95\% CI: 0.92-2.08; $\mathrm{P}=0.12)$. There was a high degree of heterogeneity $\left(\mathrm{I}^{2}=92 \% ; \mathrm{t}^{2}=0.3649 ; \mathrm{P}<0.01\right)$. There was no evidence of publication bias based on funnel plot (Figure S1).

\section{Uninodular HCC}

Among patients with uninodular disease (11 studies, 6,021 patients), there was no significant difference in pooled OS between LR and LT (HR =1.40, 95\% CI: 0.91-2.17; $\mathrm{P}=0.13)$. 
Table 2 Comparison of OS and DFS between LR and LT, overall and by subgroup

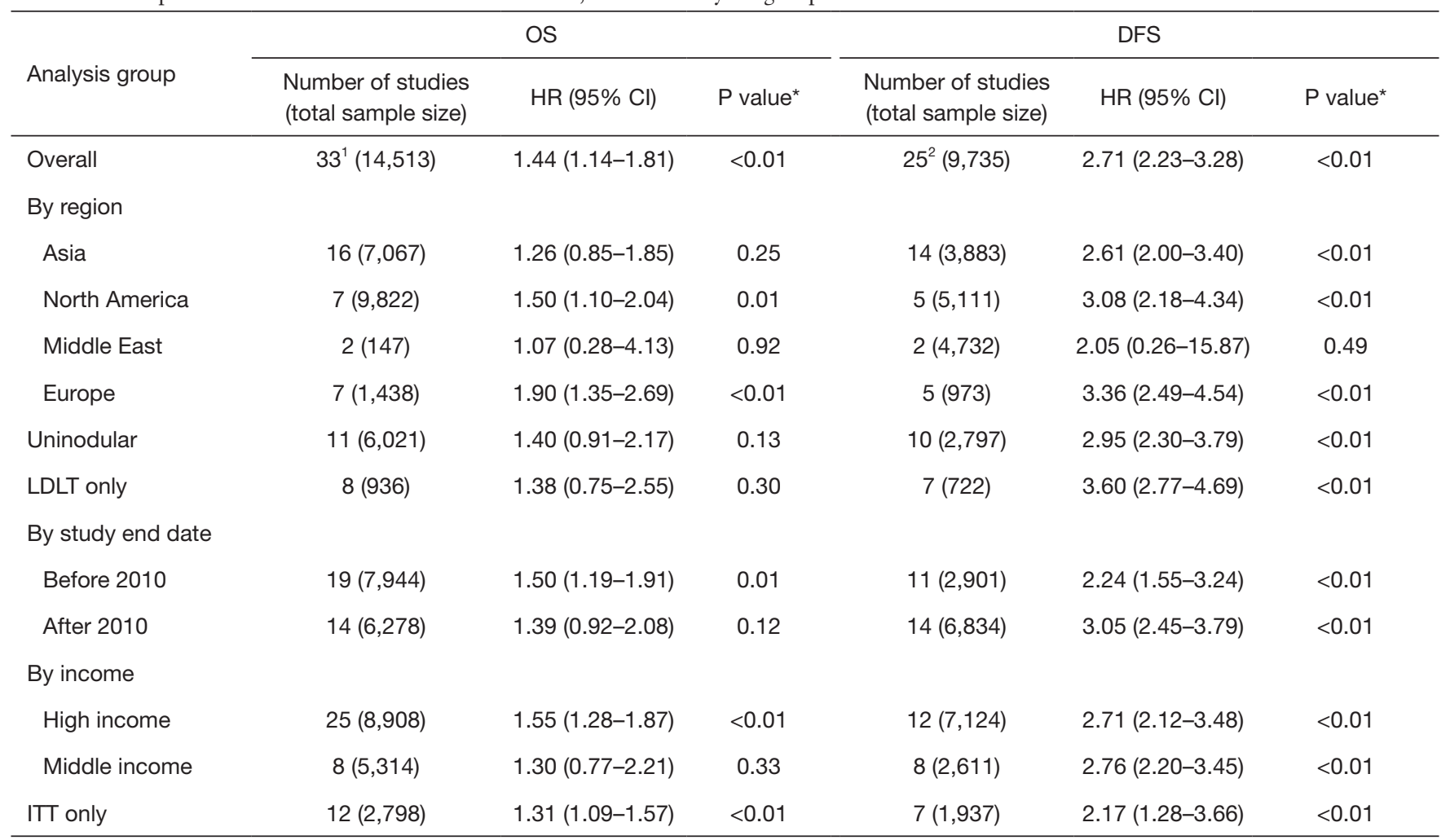

*, denotes P value comparing HR of LR versus LT; ${ }^{1}$, Of 35 studies, only 33 studies reported overall survival; ${ }^{2}$, Of 35 studies, only 25 studies reported disease-free survival. OS, overall survival; DFS, disease-free survival; LR, liver resection; LT, liver transplantation; HR, hazard ratio; $\mathrm{Cl}$, confidence interval; LDLT, living donor liver transplantation; ITT, intention-to-treat analysis.

\section{Region and income}

In patients undergoing treatment in centres from Europe (7 studies, 1,438 patients) and North America (7 studies, 9,822 patients), LR was associated with poorer OS when compared with LT (HR $=1.90 ; 95 \%$ CI: $1.35-2.69 ; \mathrm{P}<0.01$ and $\mathrm{HR}=1.50 ; 95 \% \mathrm{CI}: 1.10-2.04 ; \mathrm{P}<0.01$ respectively) (Table 2). However, there was no significant difference in pooled OS between LR and LT among studies conducted in Asia (16 studies, 7,067 patients HR $=1.26$; $95 \%$ CI: 0.85 $1.85 ; \mathrm{P}=0.25$ ) and the Middle East ( 2 studies, 147 patients HR $=1.07 ; 95 \%$ CI: 0.28-4.13; $\mathrm{P}=0.92)$. In terms of income level, LR was associated with poorer OS among patients from high income countries (HR $=1.55$; $95 \%$ CI: $1.28-1.87$; $\mathrm{P}<0.01)$. In patients from middle income countries, there was no significant difference in OS ( $\mathrm{HR}=1.30 ; 95 \% \mathrm{CI}$ : $0.77-2.21 ; \mathrm{P}=0.33)$.

\section{LDLT}

When analysis was limited to LDLT-only studies (8 studies, 936 patients), there was no significant difference in
OS between LT and LR groups (HR $=1.38$; 95\% CI: 0.75-2.55; $\mathrm{P}=0.30)$. In LDLT-only studies conducted in Asian transplant centres (7 studies, 722 patients), OS also did not differ significantly (HR $=1.16 ; 95 \%$ CI: 0.71-1.89; $\mathrm{P}=0.565)$.

\section{Postoperative surveillance strategy}

In patients following an enhanced surveillance strategy, there was no significant difference in pooled OS between LR and LT (13 studies, 3,193 patients, HR $=1.15$; 95\% CI: $0.87-1.51 ; \mathrm{P}=0.33$, Figure 3). By contrast, among studies that did not utilize enhanced postoperative surveillance (4 studies, 720 patients), LR was associated with poorer OS versus LT $(\mathrm{HR}=1.95$; 95\% CI: $1.24-3.07 ; \mathrm{P}<0.01)$.

\section{DFS}

\section{Overall, and by time period}

In total 25 studies (9,735 patients) provided data for analysis of DFS. Patients undergoing LR had poorer DFS compared to LT (HR $=2.71 ; 95 \%$ CI: $2.23-3.28 ; \mathrm{P}<0.01$, Figure 4). 


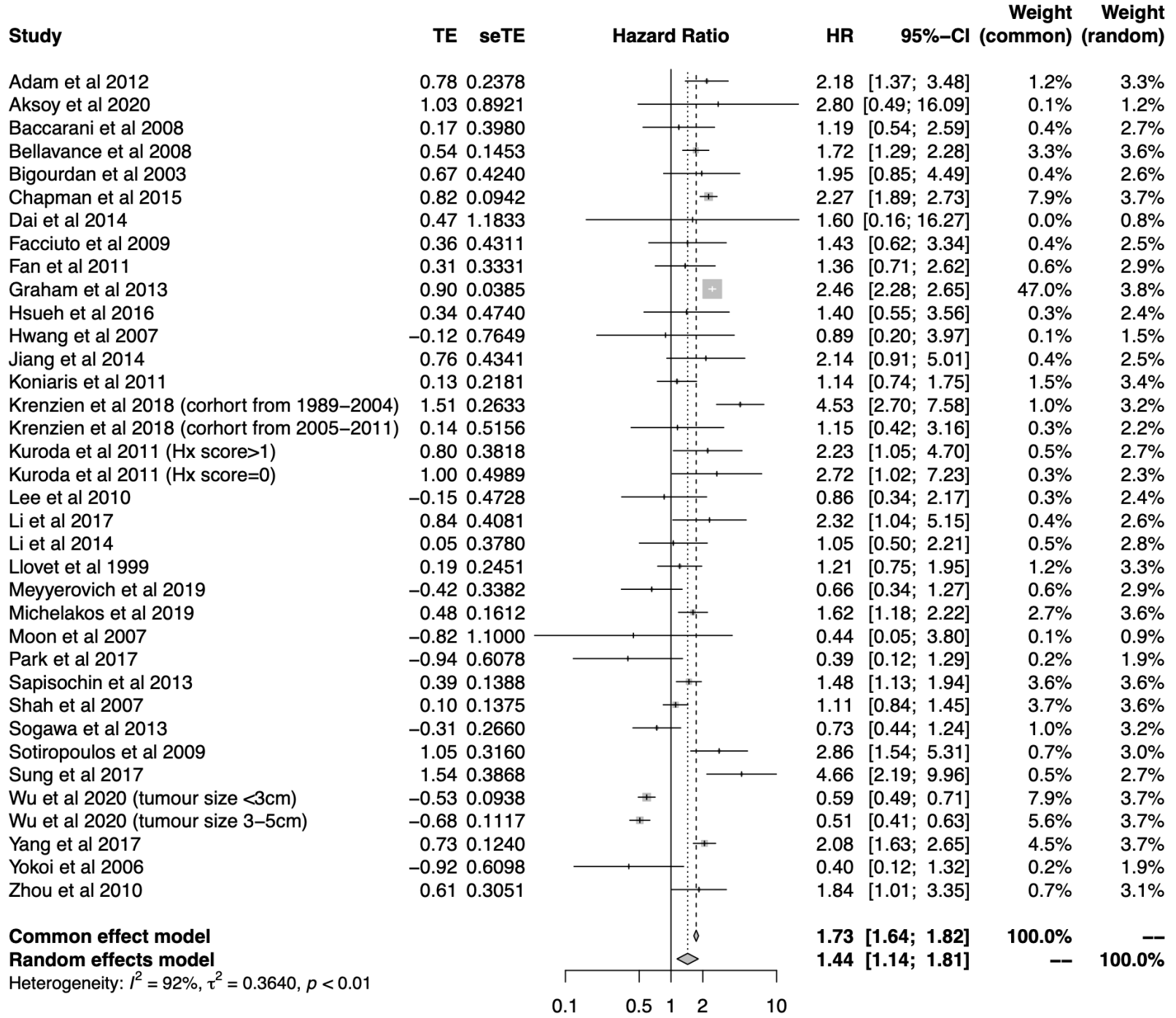

Figure 2 Forest plot for OS among patients who underwent LR versus LT for HCC. HR, hazard ratio; CI, confidence interval; OS, overall survival; LR, liver resection; LT, liver transplantation; HCC, hepatocellular carcinoma.

When results were stratified by date of study completion, patients undergoing LT had improved DFS among both studies completed before (HR $=2.24 ; 95 \%$ CI: $1.55-3.24$; $\mathrm{P}<0.01$ ) and after 2010 (HR $=3.05$; 95\% CI: 2.45-3.79; $\mathrm{P}<0.01)$. There was a moderate degree of heterogeneity $\left(\mathrm{I}^{2}=64 \% ; \mathrm{t}^{2}=0.1262, \mathrm{P}<0.01\right)$. There was no evidence of publication bias based on the funnel plot (Figure S2).

\section{Uninodular HCC}

Among patients with uninodular disease only (10 studies, 2,797 patients), LR was associated with poorer DFS compared with LT $(\mathrm{HR}=2.95 ; 95 \%$ CI: 2.30-3.79; $\mathrm{P}<0.01)$.

By region and income

Among studies from Asia (14 studies, 3,883 patients HR $=2.61 ; 95 \%$ CI: $2.00-3.40 ; \mathrm{P}<0.01$ ), Europe (5 studies, 973 patients HR $=3.03 ; 95 \%$ CI: $2.01-4.59$; $\mathrm{P}<0.01$ ), and North America (5 studies, 5,111 patients HR =3.08; 95\% CI: 2.18-4.34; $\mathrm{P}<0.01)$, DFS was improved in patients that underwent LT compared to LR. In terms of income, LT was associated with significantly improved DFS compared to LR in both high (12 studies, 7,124 patients 


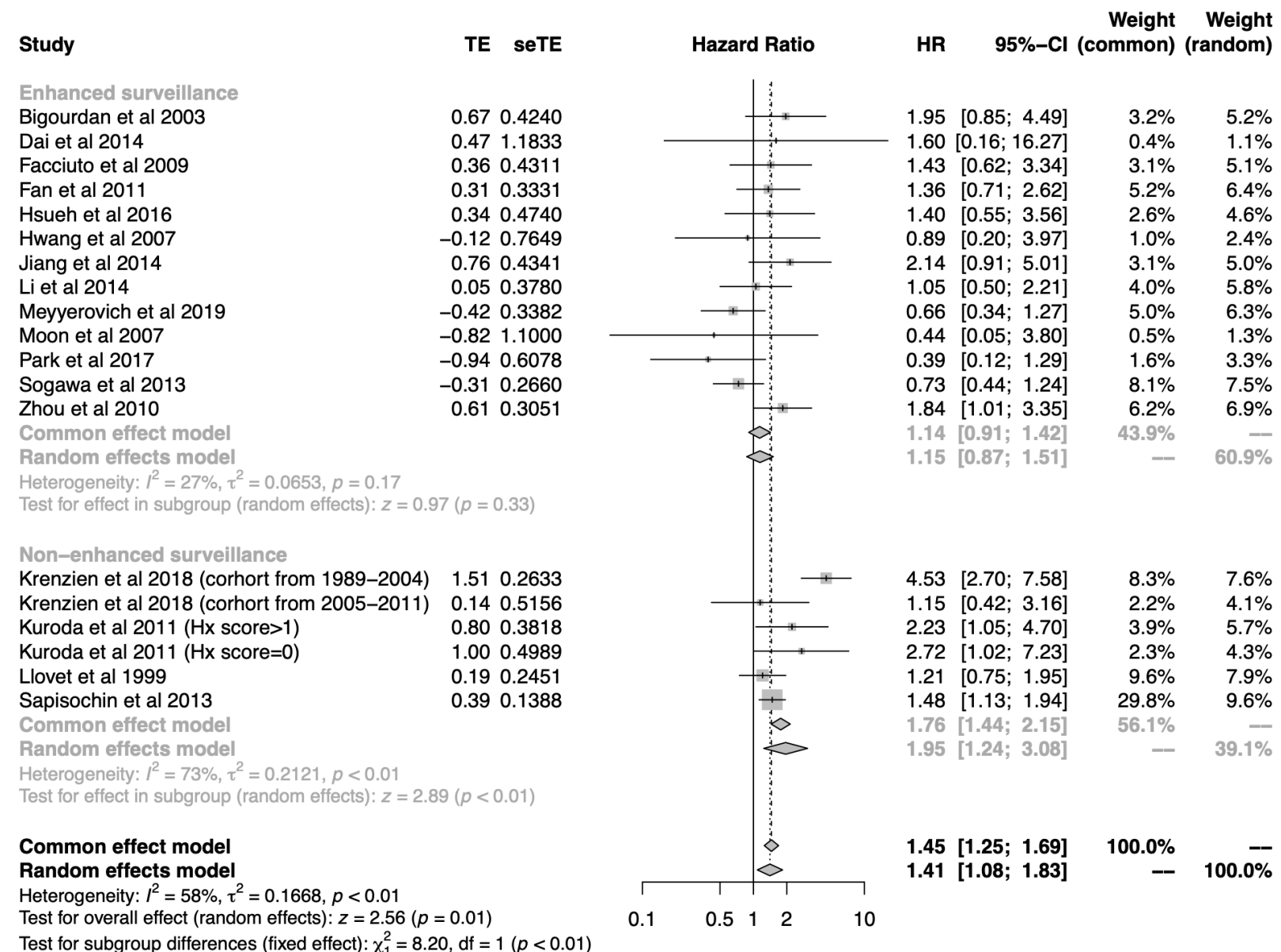

Figure 3 Forest plot for OS among patients who underwent LR versus LT, by surveillance strategy. HR, hazard ratio; CI, confidence interval; OS, overall survival; LR, liver resection; LT, liver transplantation.

$\mathrm{HR}=2.71 ; 95 \% \mathrm{CI}: 2.12-3.48 ; \mathrm{P}<0.01)$ and middle-income countries ( 8 studies, 2,611 patients $\mathrm{HR}=2.76$; $95 \% \mathrm{CI}$ : 2.20-3.45; $\mathrm{P}<0.01)$.

\section{LDLT}

A sensitivity analysis was conducted for LDLT-only studies (7 studies, 722 patients). LT was associated with improved DFS compared to $\mathrm{LR}(\mathrm{HR}=3.60 ; 95 \% \mathrm{CI}: 2.77-4.69$; $\mathrm{P}<0.01)$. Additionally, when studies were further stratified by region, LDLT-only studies from Asian transplant centres (5 studies, 690 patients) continued to report improved DFS in patients that had underwent LT compared to LR (HR =3.16; 95\% CI: 2.30-4.34; $\mathrm{P}<0.001)$.

\section{Meta-regression of factors associated with survival and DFS}

Meta-regression of study-level demographic, clinical, and biochemical characteristics for potentially relevant factors with sufficient data revealed that NASH was associated with increased HR for DFS between LR and LT. This suggests that in patients with NASH, LT was associated with relatively improved DFS compared to LR ( $\beta=8.17 ; 95 \%$ CI: 3.99-12.35; $\mathrm{P}<0.01$ ) (Table 3).

\section{Sensitivity analyses for ITT studies}

Analysis for OS among ITT studies (12 studies, 2,798 patients) showed a similar result to the main analysis, 


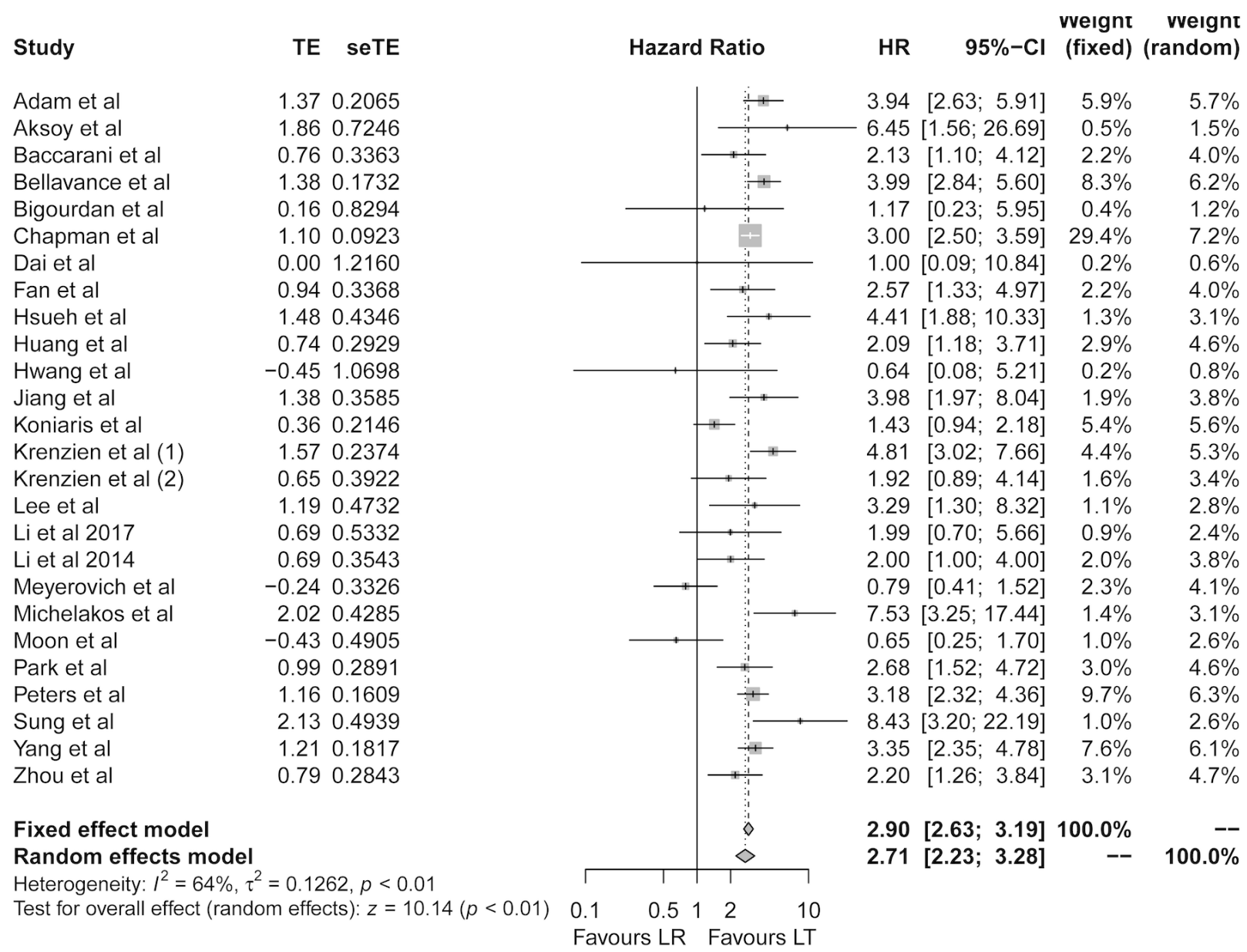

Figure 4 Forest plot for DFS among patients who underwent LR versus LT for HCC. HR, hazard ratio; CI, confidence interval; DFS, disease-free survival; LR, liver resection; LT, liver transplantation; HCC, hepatocellular carcinoma.

with a poorer OS $(\mathrm{HR}=1.31 ; 95 \% \mathrm{CI}: 1.09-1.57 ; \mathrm{P}<0.01)$ (Figure S3) among LR versus LT patients. Analysis for DFS among ITT studies (7 studies, 1,937 patients) showed that DFS remained poorer among LR versus LT patients $(\mathrm{HR}=2.17 ; 95 \% \mathrm{CI}: 1.28-3.66 ; \mathrm{P}<0.01)$ (Figure S4).

\section{Discussion}

In this meta-analysis of 35 studies and 18,421 HCC patients within the Milan criteria, we determined that patients who underwent LR had a poorer OS versus those who underwent LT (HR $=1.44 ; 95 \%$ CI: 1.14-1.81), with similar findings among ITT studies. In addition, patients who underwent LR had almost threefold risk of HCC recurrence (HR $=2.71 ; 95 \%$ CI: 2.23-3.28) compared with LT patients. These findings emphasize that LT remains the ideal treatment option for HCC by removing both the tumour and the surrounding diseased liver, thus addressing the field change effect and lowering the risk of recurrence (63).

However, among patients with uninodular lesions within the Milan criteria, there was no significant difference in OS between LR and LT (HR =1.40; 95\% CI: 0.91-2.17), although the risk of recurrence remained around threefold (HR $=2.95$; 95\% CI: 2.30-3.79). For such patients, LT is the ideal long-term curative treatment. However, considering graft shortages and the need for long term post-transplant immunosuppression, LR is a reasonable alternative. Our study provides useful data for care providers who are 


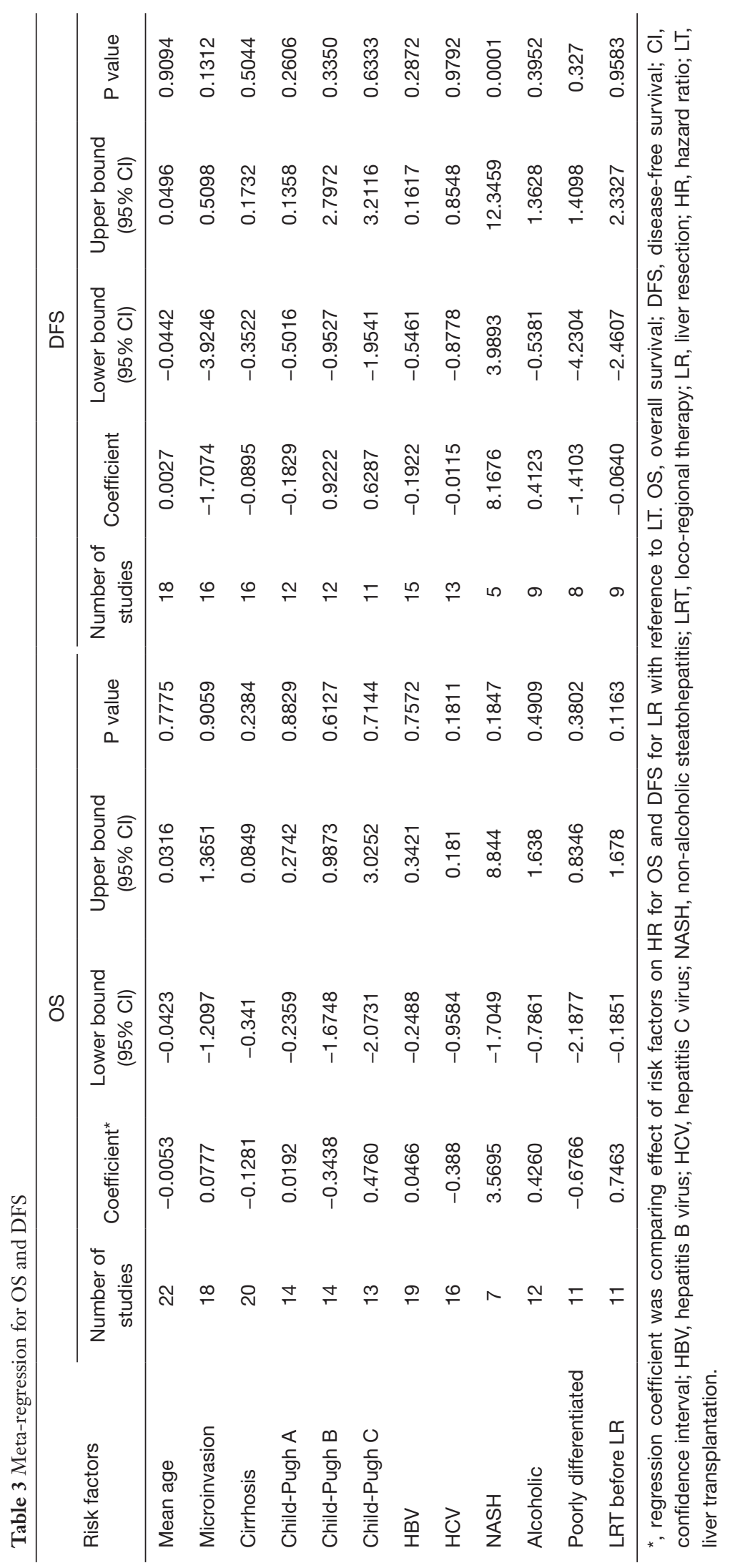


counselling patients with a single HCC lesion, especially in light of the increasing availability of LDLT as a treatment option (64).

LR was associated with poorer OS when compared to LT in North America and Europe, but not in Asia. This may be related to the lower proportion of cirrhosis among HBVrelated HCC patients in Asia $(3,8,65)$. LT among non-Asian countries are predominantly DDLTs, while LT among Asian countries are predominantly LDLTs. Among patients who underwent DDLT, the time spent on the waitlist helps to select for patients with better tumour biology, unlike LDLT, where waiting time is minimized (66). Smaller graft volume grafts used in LDLT may reduce OS in patients that underwent LT in Asian centres $(67,68)$. Furthermore, strong surveillance programs in Asia, along with the use of additional biomarkers such as protein induced by vitamin $\mathrm{K}$ absence or antagonist-II (PIVKA-II) and alpha-fetoprotein (AFP-L3) may allow for earlier detection of HCC recurrence after LR and improved survival $(6,69)$. These factors could have accounted for the lack of difference in OS between LT and LR among Asian as well as LDLT only studies. In addition, antiviral therapy for hepatitis B is well established and effective in reducing mortality after hepatectomy, which may also explain why survival after LR is comparable to that of LT in Asia, where HBV is the dominant cause of HCC (17,70-72). However, compliance to $\mathrm{HBV}$ antiviral therapy is poor, and urgent efforts are required to improve compliance and linkage to care for patients with HBV-related HCC (73). By contrast, HCV is a major cause of HCC in North America and Europe, and while direct antiviral therapy (DAA) is safe and effective in prolonging survival, DAAs have only recently become widely available. Its effect on survival after LR may only be seen in future studies (18).

Over time, it appeared that OS after LR was significantly poorer compared with LT among studies concluded prior to 2010 (HR $=1.50 ; 95 \% \mathrm{CI}: 1.19-1.91)$ but not after (HR $=1.39$; 95\% CI: $0.92-2.08$ ). This may be related to better surveillance and medical care resulting in recurrent disease detected earlier. Among studies that used enhanced surveillance, there was no significant difference in OS between LT and LR patients. This suggests that when comprehensive post-operative surveillance is performed, LR may result in a similar OS to LT through early detection of HCC recurrence allowing for earlier treatment. A study of 734 HCC patients that underwent resection found that lack of tumour surveillance was an independent predictor of mortality (74). Among hepatology guidelines, there is a lack of recommendations for surveillance after resection $(5,6,15)$, however the National Comprehensive Cancer Network guidelines suggest that imaging be obtained every 3 to 6 months for the first 2 years after surgery, then 6-12 monthly thereafter for up to 5 years (75). Of note, adherence to HCC surveillance in the real world remain poor in general, and further efforts are urgently required to improve compliance (76-78). Additional studies are required to evaluate the optimal surveillance interval after curative surgery.

We found that OS after LR was poorer when compared to LT in high income countries, but not among middle income countries. We speculate that better medical care in high income countries may have resulted in disproportionately better survival outcomes after LT versus LR by maximising the benefit of LT and reducing post-LT complications. By contrast, a lower standard of post-transplant care may result in comparable survival with patients who underwent LR, however more data are required to validate these findings.

NASH-related HCC was found to be associated with increased HR for DFS between LR and LT, suggesting that LT was associated with relatively better DFS in patients with NASH. This is contrary to available data which suggests that NASH-related HCC has a similar prognosis after curative treatment to other disease aetiologies (79). This may be related to the limitation of using study-level data, rather than individual patient data. In addition, only a modest number of studies ( $\mathrm{n}=5)$ had sufficient data for analysis of DFS in NASH, hence this result should be interpreted with caution.

\section{In context with current literature}

In contrast with a previous meta-analysis by Menahem and colleagues which reported no difference in the odds ratio for OS between LR and LT, we found that OS was significantly better for LT versus LR (13). Menahem and colleagues utilized odds ratio instead of HR to analyse survival outcomes (13), which is a less robust measure of time-dependent analysis that does not account for censoring of data (80). By contrast, we used HR to compare OS which allows for more accurate time-dependent analysis and performed additional analyses by region, time period, income, and the use of enhanced surveillance. In addition, we were able to provide pooled data for uninodular lesions within Milan which was not available in the prior study by Menahem et al. (13). Despite our findings emphasizing 
the survival advantage of LT versus LR, we recognize that many patients lack access to LT, especially in countries with low organ donation rates. In addition, even in countries where donor organs are more readily available, patients may still opt for LR over LT due to avoid the need for longterm immunosuppression. In these situations, should there be HCC recurrence after LR, salvage LT may still be a possible treatment option.

\section{Strengths and limitations}

This large meta-analysis provides a thorough and updated comparison of survival outcomes following LT and LR. However, there are several limitations to this study. Firstly, there are inherent selection biases in retrospective studies. While we have limited our included studies to patients within the Milan criteria, other features such as age are not strictly comparable in different studies. Proportion of cirrhosis was also significantly lower in the LR group, which could have partially confounded our findings. Furthermore, given that only retrospective studies were available for inclusion, this has led to a higher level of heterogeneity. In addition, there were limited studies available for the metaregression of some baseline characteristics on survival outcomes, which reduces the statistical power for the analysis of risk factors. Finally, there was paucity of data from Africa and South America, which highlights the need for more studies from these regions.

\section{Conclusions}

In summary, we found that mortality was nearly $50 \%$ higher among patients with HCC treated with LR versus LT. Patients who underwent LR had a threefold higher risk of recurrent disease compared with LT recipients. However, survival was similar between patients with uninodular disease who underwent LR and LT. Survival after LR and LT was also similar in Asia, where LDLT predominates, but not in North America and Europe. In addition, survival was similar among LR and LT patients who underwent enhanced surveillance after surgery but was poorer among LR patients who underwent usual surveillance. Greater efforts are required to improve adherence to surveillance for HCC recurrence, especially after LR.

\section{Acknowledgments}

Funding: None.

\section{Footnote}

Reporting Checklist: The authors have completed the PRISMA reporting checklist. Available at https://hbsn. amegroups.com/article/view/10.21037/hbsn-21-350/rc

Conflicts of Interest: All authors have completed the ICMJE uniform disclosure form (available at https://hbsn. amegroups.com/article/view/10.21037/hbsn-21-350/coif). The authors have no conflicts of interest to declare.

Ethical Statement: The authors are accountable for all aspects of the work in ensuring that questions related to the accuracy or integrity of any part of the work are appropriately investigated and resolved.

Open Access Statement: This is an Open Access article distributed in accordance with the Creative Commons Attribution-NonCommercial-NoDerivs 4.0 International License (CC BY-NC-ND 4.0), which permits the noncommercial replication and distribution of the article with the strict proviso that no changes or edits are made and the original work is properly cited (including links to both the formal publication through the relevant DOI and the license). See: https://creativecommons.org/licenses/by-nc-nd/4.0/.

\section{References}

1. Bray F, Ferlay J, Soerjomataram I, et al. Global cancer statistics 2018: GLOBOCAN estimates of incidence and mortality worldwide for 36 cancers in 185 countries. CA Cancer J Clin 2018;68:394-424.

2. Sung H, Ferlay J, Siegel RL, et al. Global Cancer Statistics 2020: GLOBOCAN Estimates of Incidence and Mortality Worldwide for 36 Cancers in 185 Countries. CA Cancer J Clin 2021;71:209-49.

3. Llovet JM, Kelley RK, Villanueva A, et al. Hepatocellular carcinoma. Nat Rev Dis Primers 2021;7:6.

4. Heimbach JK, Kulik LM, Finn RS, et al. AASLD guidelines for the treatment of hepatocellular carcinoma. Hepatology 2018;67:358-80.

5. European Association for the Study of the Liver. Electronic address: easloffice@easloffice.eu; European Association for the Study of the Liver. EASL Clinical Practice Guidelines: Management of hepatocellular carcinoma. J Hepatol 2018;69:182-236.

6. Omata M, Cheng AL, Kokudo N, et al. Asia-Pacific clinical practice guidelines on the management of 
hepatocellular carcinoma: a 2017 update. Hepatol Int 2017;11:317-70.

7. Huang DQ, Muthiah MD, Zhou L, et al. Predicting HCC Response to Multikinase Inhibitors With In Vivo Cirrhotic Mouse Model for Personalized Therapy. Cell Mol Gastroenterol Hepatol 2021;11:1313-25.

8. Yang JD, Hainaut P, Gores GJ, et al. A global view of hepatocellular carcinoma: trends, risk, prevention and management. Nat Rev Gastroenterol Hepatol 2019;16:589-604.

9. Song P, Cai Y, Tang H, et al. The clinical management of hepatocellular carcinoma worldwide: A concise review and comparison of current guidelines from 2001 to 2017. Biosci Trends 2017;11:389-98.

10. Mehta N, Yao FY. What Are the Optimal Liver Transplantation Criteria for Hepatocellular Carcinoma? Clin Liver Dis (Hoboken) 2019;13:20-5.

11. Tan DJH, Wong C, Ng CH, et al. A Meta-Analysis on the Rate of Hepatocellular Carcinoma Recurrence after Liver Transplant and Associations to Etiology, Alpha-Fetoprotein, Income and Ethnicity. J Clin Med 2021;10:238.

12. Parikh ND, Hutton D, Marrero W, et al. Projections in donor organs available for liver transplantation in the United States: 2014-2025. Liver Transpl 2015;21:855-63.

13. Menahem B, Lubrano J, Duvoux C, et al. Liver transplantation versus liver resection for hepatocellular carcinoma in intention to treat: An attempt to perform an ideal meta-analysis. Liver Transpl 2017;23:836-44.

14. Mazzaferro V, Regalia E, Doci R, et al. Liver transplantation for the treatment of small hepatocellular carcinomas in patients with cirrhosis. $\mathrm{N}$ Engl J Med 1996;334:693-9.

15. Marrero JA, Kulik LM, Sirlin CB, et al. Diagnosis, Staging, and Management of Hepatocellular Carcinoma: 2018 Practice Guidance by the American Association for the Study of Liver Diseases. Hepatology 2018;68:723-50.

16. Taefi A, Abrishami A, Nasseri-Moghaddam S, et al. Surgical resection versus liver transplant for patients with hepatocellular carcinoma. Cochrane Database Syst Rev 2013;(6):CD006935.

17. Chen VL, Yeh ML, Le AK, et al. Anti-viral therapy is associated with improved survival but is underutilised in patients with hepatitis B virus-related hepatocellular carcinoma: real-world east and west experience. Aliment
Pharmacol Ther 2018;48:44-54.

18. Dang H, Yeo YH, Yasuda S, et al. Cure With InterferonFree Direct-Acting Antiviral Is Associated With Increased Survival in Patients With Hepatitis C Virus-Related Hepatocellular Carcinoma From Both East and West. Hepatology 2020;71:1910-22.

19. Page MJ, McKenzie JE, Bossuyt PM, et al. The PRISMA 2020 statement: an updated guideline for reporting systematic reviews. BMJ 2021;372:n71.

20. Fantom N, Umar S. The World Bank's Classification of Countries by Income. Policy Research Working Paper 2016. Available online: https://openknowledge.worldbank. org/handle/10986/23628

21. Higgins JP, Thompson SG, Deeks JJ, et al. Measuring inconsistency in meta-analyses. BMJ 2003;327:557-60.

22. Fletcher J. What is heterogeneity and is it important? BMJ 2007;334:94-6.

23. Tufanaru C, Munn Z, Stephenson M, et al. Fixed or random effects meta-analysis? Common methodological issues in systematic reviews of effectiveness. Int J Evid Based Healthc 2015;13:196-207.

24. Wells G, Shea B, O'Connell D, et al. The NewcastleOttawa Scale (NOS) for Assessing the Quality of Non-Randomized Studies in Meta-Analysis 2014. Available online: http://www.ohri.ca/programs/clinical_ epidemiology/oxford.asp

25. Sedgwick $P$. What is publication bias in a meta-analysis? BMJ 2015;351:h4419.

26. Dai Y, Li C, Wen TF, et al. Comparison of liver resection and transplantation for Child-pugh A cirrhotic patient with very early hepatocellular carcinoma and portal hypertension. Pak J Med Sci 2014;30:996-1000.

27. Huang H, Liang P, Yu XL, et al. Safety assessment and therapeutic efficacy of percutaneous microwave ablation therapy combined with percutaneous ethanol injection for hepatocellular carcinoma adjacent to the gallbladder. Int J Hyperthermia 2015;31:40-7.

28. Jiang L, Liao A, Wen T, et al. Living donor liver transplantation or resection for Child-Pugh A hepatocellular carcinoma patients with multiple nodules meeting the Milan criteria. Transpl Int 2014;27:562-9.

29. Li C, Liu JY, Peng W, et al. Liver resection versus transplantation for multiple hepatocellular carcinoma: a propensity score analysis. Oncotarget 2017;8:81492-500.

30. Li C, Zhu WJ, Wen TF, et al. Child-Pugh A hepatitis 
B-related cirrhotic patients with a single hepatocellular carcinoma up to $5 \mathrm{~cm}$ : liver transplantation vs. resection. J Gastrointest Surg 2014;18:1469-76.

31. Wu Z, Chen W, Ouyang T, et al. Management and survival for patients with stage-I hepatocellular carcinoma: An observational study based on SEER database. Medicine (Baltimore) 2020;99:e22118.

32. Yang A, Ju W, Yuan X, et al. Comparison between liver resection and liver transplantation on outcomes in patients with solitary hepatocellular carcinoma meeting UNOS criteria: a population-based study of the SEER database. Oncotarget 2017;8:97428-38.

33. Zhou J, Wang Z, Qiu SJ, et al. Surgical treatment for early hepatocellular carcinoma: comparison of resection and liver transplantation. J Cancer Res Clin Oncol 2010;136:1453-60.

34. Chapman WC, Klintmalm G, Hemming A, et al. Surgical treatment of hepatocellular carcinoma in North America: can hepatic resection still be justified? J Am Coll Surg 2015;220:628-37.

35. Facciuto ME, Rochon C, Pandey M, et al. Surgical dilemma: liver resection or liver transplantation for hepatocellular carcinoma and cirrhosis. Intention-to-treat analysis in patients within and outwith Milan criteria. HPB (Oxford) 2009;11:398-404.

36. Graham JA, Newman DA, Smirniotopolous J, et al. Transplantation for hepatocellular carcinoma in younger patients has an equivocal survival advantage as compared with resection. Transplant Proc 2013;45:265-71.

37. Koniaris LG, Levi DM, Pedroso FE, et al. Is surgical resection superior to transplantation in the treatment of hepatocellular carcinoma? Ann Surg 2011;254:527-37; discussion 537-8.

38. Michelakos T, Xourafas D, Qadan M, et al. Hepatocellular Carcinoma in Transplantable Child-Pugh A Cirrhotics: Should Cost Affect Resection vs Transplantation? J Gastrointest Surg 2019;23:1135-42.

39. Peters NA, Javed AA, He J, et al. Association of socioeconomics, surgical therapy, and survival of early stage hepatocellular carcinoma. J Surg Res 2017;210:253-60.

40. Sogawa H, Shrager B, Jibara G, et al. Resection or transplant-listing for solitary hepatitis $\mathrm{C}$-associated hepatocellular carcinoma: an intention-to-treat analysis. HPB (Oxford) 2013;15:134-41.

41. Hwang S, Lee SG, Lee YJ, et al. Prognostic impact of sarcomatous change of hepatocellular carcinoma in patients undergoing liver resection and liver transplantation. J Gastrointest Surg 2008;12:718-24.

42. Lee KK, Kim DG, Moon IS, et al. Liver transplantation versus liver resection for the treatment of hepatocellular carcinoma. J Surg Oncol 2010;101:47-53.

43. Moon DB, Lee SG, Hwang S. Liver transplantation for hepatocellular carcinoma: single nodule with Child-Pugh class A sized less than $3 \mathrm{~cm}$. Dig Dis 2007;25:320-8.

44. Park MS, Lee KW, Kim H, et al. Primary Livingdonor Liver Transplantation Is Not the Optimal Treatment Choice in Patients With Early Hepatocellular Carcinoma With Poor Tumor Biology. Transplant Proc 2017;49:1103-8.

45. Sung PS, Yang H, Na GH, et al. Long-Term Outcome of Liver Resection Versus Transplantation for Hepatocellular Carcinoma in a Region Where Living Donation is a Main Source. Ann Transplant 2017;22:276-84.

46. Adam R, Bhangui P, Vibert E, et al. Resection or transplantation for early hepatocellular carcinoma in a cirrhotic liver: does size define the best oncological strategy? Ann Surg 2012;256:883-91.

47. Bigourdan JM, Jaeck D, Meyer N, et al. Small hepatocellular carcinoma in Child A cirrhotic patients: hepatic resection versus transplantation. Liver Transpl 2003;9:513-20.

48. Krenzien F, Schmelzle M, Struecker B, et al. Liver Transplantation and Liver Resection for Cirrhotic Patients with Hepatocellular Carcinoma: Comparison of LongTerm Survivals. J Gastrointest Surg 2018;22:840-8.

49. Sotiropoulos GC, Drühe N, Sgourakis G, et al. Liver transplantation, liver resection, and transarterial chemoembolization for hepatocellular carcinoma in cirrhosis: which is the best oncological approach? Dig Dis Sci 2009;54:2264-73.

50. Kuroda S, Tashiro H, Kobayashi T, et al. Selection criteria for hepatectomy in patients with hepatocellular carcinoma classified as Child-Pugh class B. World J Surg 2011;35:834-41.

51. Yokoi H, Isaji S, Yamagiwa K, et al. The role of livingdonor liver transplantation in surgical treatment for hepatocellular carcinoma. J Hepatobiliary Pancreat Surg 2006;13:123-30.

52. Llovet JM, Fuster J, Bruix J. Intention-to-treat analysis of surgical treatment for early hepatocellular carcinoma: resection versus transplantation. Hepatology 
1999;30:1434-40.

53. Sapisochin G, Castells L, Dopazo C, et al. Single HCC in cirrhotic patients: liver resection or liver transplantation? Long-term outcome according to an intention-to-treat basis. Ann Surg Oncol 2013;20:1194-202.

54. Shah SA, Cleary SP, Tan JC, et al. An analysis of resection vs transplantation for early hepatocellular carcinoma: defining the optimal therapy at a single institution. Ann Surg Oncol 2007;14:2608-14.

55. Baccarani U, Isola M, Adani GL, et al. Superiority of transplantation versus resection for the treatment of small hepatocellular carcinoma. Transpl Int 2008;21:247-54.

56. Fan ST, Poon RT, Yeung C, et al. Outcome after partial hepatectomy for hepatocellular cancer within the Milan criteria. Br J Surg 2011;98:1292-300.

57. Meyerovich G, Goykhman Y, Nakache R, et al. Resection vs Transplant Listing for Hepatocellular Carcinoma: An Intention-to-Treat Analysis. Transplant Proc 2019;51:1867-73.

58. Hsueh KC, Lee TY, Kor CT, et al. The role of liver transplantation or resection for patients with early hepatocellular carcinoma. Tumour Biol 2016;37:4193-201.

59. Aksoy SO, Unek T, Sevinc AI, et al. Comparison of Resection and Liver Transplant in Treatment of Hepatocellular Carcinoma. Exp Clin Transplant 2020;18:712-8.

60. Bellavance EC, Lumpkins KM, Mentha G, et al. Surgical management of early-stage hepatocellular carcinoma: resection or transplantation? J Gastrointest Surg 2008;12:1699-708.

61. Huang ZY, Liang BY, Xiong M, et al. Severity of cirrhosis should determine the operative modality for patients with early hepatocellular carcinoma and compensated liver function. Surgery 2016;159:621-31.

62. Hwang S, Lee SG, Moon DB, et al. Salvage living donor liver transplantation after prior liver resection for hepatocellular carcinoma. Liver Transpl 2007;13:741-6.

63. Sapisochin G, Bruix J. Liver transplantation for hepatocellular carcinoma: outcomes and novel surgical approaches. Nat Rev Gastroenterol Hepatol 2017;14:203-17.

64. Lai Q, Sapisochin G, Gorgen A, et al. Evaluation of the Intention-to-Treat Benefit of Living Donation in Patients With Hepatocellular Carcinoma Awaiting a Liver Transplant. JAMA Surg 2021;156:e213112.

65. Huang DQ, Hoang JK, Leong J, et al. Differential characteristics and outcomes of Asian and non-Asian patients with $\mathrm{HBV}$-related hepatocellular carcinoma. Liver Int 2021;41:1922-32.

66. Choo SP, Tan WL, Goh BKP, et al. Comparison of hepatocellular carcinoma in Eastern versus Western populations. Cancer 2016;122:3430-46.

67. Nishizaki T, Ikegami T, Hiroshige S, et al. Small graft for living donor liver transplantation. Ann Surg 2001;233:575-80.

68. Chen CL, Kabiling CS, Concejero AM. Why does living donor liver transplantation flourish in Asia? Nat Rev Gastroenterol Hepatol 2013;10:746-51.

69. Tateishi R, Shiina S, Yoshida H, et al. Prediction of recurrence of hepatocellular carcinoma after curative ablation using three tumor markers. Hepatology 2006;44:1518-27.

70. Huang DQ, Lim SG. Hepatitis B: Who to treat? A critical review of international guidelines. Liver Int 2020;40 Suppl 1:5-14.

71. Chan AC, Chok KS, Yuen WK, et al. Impact of antiviral therapy on the survival of patients after major hepatectomy for hepatitis B virus-related hepatocellular carcinoma. Arch Surg 2011;146:675-81.

72. Hung IF, Poon RT, Lai CL, et al. Recurrence of hepatitis B-related hepatocellular carcinoma is associated with high viral load at the time of resection. Am J Gastroenterol 2008;103:1663-73.

73. Huang DQ, Nguyen MH. Treatment eligibility in hepatitis B: a call for better linkage to optimal care. Lancet Gastroenterol Hepatol 2021;6:160.

74. Xu XF, Xing H, Han J, et al. Risk Factors, Patterns, and Outcomes of Late Recurrence After Liver Resection for Hepatocellular Carcinoma: A Multicenter Study From China. JAMA Surg 2019;154:209-17.

75. Benson AB, D'Angelica MI, Abbott DE, et al. Hepatobiliary Cancers, Version 2.2021, NCCN Clinical Practice Guidelines in Oncology. J Natl Compr Canc Netw 2021;19:541-65.

76. Wolf E, Rich NE, Marrero JA, et al. Use of Hepatocellular Carcinoma Surveillance in Patients With Cirrhosis: A Systematic Review and Meta-Analysis. Hepatology 2021;73:713-25.

77. Huang DQ, Yeo YH, Nguyen MH. Letter to the Editor: Hepatocellular Carcinoma Surveillance in Cirrhosis Patients: Is the Real-World Situation Even Worse Than Reported? Hepatology 2021;74:1714-5.

78. Huang DQ, Hoang JK, Nguyen MH. HBV-related hepatocellular carcinoma: A call to improve surveillance 
and linkage to care. Liver Int 2021;41:2238-9.

79. Huang DQ, El-Serag HB, Loomba R. Global epidemiology of NAFLD-related HCC: trends, predictions, risk factors and prevention. Nat Rev
Cite this article as: Koh JH, Tan DJH, Ong Y, Lim WH, Ng CH, Tay PWL, Yong JN, Muthiah MD, Tan EX, Pang NQ, Kim BK, Syn N, Kow A, Goh BKP, Huang DQ. Liver resection versus liver transplantation for hepatocellular carcinoma within Milan criteria: a meta-analysis of 18,421 patients. HepatoBiliary Surg Nutr 2022;11(1):78-93. doi: 10.21037/hbsn-21-350
Gastroenterol Hepatol 2021;18:223-38.

80. George A, Stead TS, Ganti L. What's the Risk: Differentiating Risk Ratios, Odds Ratios, and Hazard Ratios? Cureus 2020;12:e10047. 


\section{Supplementary}

\section{Appendix 1}

\section{Search Strategy for Medline}

1. (((hepat* or liver $\left.^{*}\right)$ adj3 (carcinoma* or tumour* or tumor* ${ }^{*}$ or neoplasm* or malign* or cancer*)) or HCC).tw.

2. ((liver* or hepat $\left.^{*}\right)$ adj3 (transplant* or graft*)).tw.

3. ((liver or hepatic) adj3 (resection* or segmentectom*)) or hepatectomy*).tw.

4. \#1 and \#2 and \#3

\section{Search Strategy for Embase}

1. (((hepat* or liver*) NEAR/3 (carcinoma* or tumour* or tumor* or neoplasm* or malign* or cancer*)) or HCC):ti,ab

2. ((liver* or hepat*) NEAR/3 (transplant* or graft*)):ti,ab

3. ((liver or hepatic) NEAR/3 (resection* or segmentectom*)) or hepatectomy*):ti,ab

4. \#1 and \#2 and \#3 
Table S1 Characteristics of included studies

\begin{tabular}{|c|c|c|c|c|c|c|c|c|c|c|c|c|c|}
\hline Author & Country/region & $\begin{array}{l}\text { Study } \\
\text { duration }\end{array}$ & $\begin{array}{c}\text { Total population } \\
(\mathrm{LT})\end{array}$ & $\begin{array}{c}\text { Total } \\
\text { population (LR) }\end{array}$ & $\begin{array}{c}\text { Surveillance } \\
\text { method }\end{array}$ & $\begin{array}{l}\text { Median follow-up } \\
\text { (months) }\end{array}$ & $\begin{array}{c}\text { Age } \\
\text { (years) }\end{array}$ & Male (\%) & Cirrhosis (\%) & $\begin{array}{c}\text { Mean AFP } \\
\text { (ng/Ml) }\end{array}$ & $\begin{array}{l}\text { Mean tumour } \\
\text { size }(\mathrm{cm})\end{array}$ & $\begin{array}{l}\text { Microvascular } \\
\text { invasion (\%) }\end{array}$ & $\begin{array}{l}\text { Uninodular } \\
\text { tumour (\%) }\end{array}$ \\
\hline $\begin{array}{l}\text { Adam et al., } \\
2012\end{array}$ & France & 1990-2010 & 97 & 101 & - & LT: 83; LR: 36 & 58.58 & 85.35 & 100.00 & - & 2.71 & 42.31 & 100 \\
\hline $\begin{array}{l}\text { Aksoy et al., } \\
2020\end{array}$ & Turkey & 1998-2010 & 33 & 27 & - & $\begin{array}{c}\text { LT: } 34.5 \text { (mean); LR: } \\
29.0 \text { (mean) }\end{array}$ & - & - & - & - & - & - & - \\
\hline $\begin{array}{l}\text { Baccarani et al., } \\
2008\end{array}$ & Italy & 1996-2005 & 48 & 38 & - & & 62.99 & 81.40 & 100.00 & - & 3.61 & 17.28 & - \\
\hline $\begin{array}{l}\text { Bellavance et al., } \\
2008\end{array}$ & $\begin{array}{l}\text { USA, Switzerland, } \\
\text { Portugal, Italy }\end{array}$ & 1985-2008 & 245 & 134 & - & LT: 39.6; LR: 27.6 & - & 82.36 & 100.00 & 276.00 & - & 5.79 & 100 \\
\hline $\begin{array}{l}\text { Bigourdan et al., } \\
2003\end{array}$ & France & 1991-1999 & 17 & 20 & Enhanced & & 63.55 & 38.59 & 100.00 & 118.00 & 3.31 & 8.11 & - \\
\hline $\begin{array}{l}\text { Chapman et al., } \\
2015\end{array}$ & USA & 1990-2011 & 248 & 496 & - & & 60.07 & 71.00 & 58.67 & 123.00 & - & - & 100 \\
\hline Dai et al., 2014 & China & 2008-2013 & 25 & 13 & Enhanced & & 45.56 & 90.83 & 100.00 & - & 1.76 & 24.35 & 100 \\
\hline $\begin{array}{l}\text { Facciuto et al., } \\
2009\end{array}$ & USA & 1997-2007 & 66 & 25 & Enhanced & LT: 28; LR:24 & - & - & - & - & - & - & - \\
\hline Fan et al., 2011 & Hong Kong & 1995-2008 & 287 & 50 & Enhanced & LT: 55.3; LR: 55.3 & 51.14 & 11.71 & - & - & - & - & 100 \\
\hline $\begin{array}{l}\text { Graham et al., } \\
2013\end{array}$ & USA & 1998-2008 & 2,355 & 1,873 & - & & - & - & - & - & - & - & - \\
\hline $\begin{array}{l}\text { Hsueh et al., } \\
2016\end{array}$ & Taiwan & 2006-2013 & 184 & 65 & Enhanced & & 55.42 & 62.21 & 62.65 & 412.84 & 2.71 & 23.29 & - \\
\hline $\begin{array}{l}\text { Huang et al., } \\
2016\end{array}$ & China & 2001-2009 & 51 & 256 & Enhanced & LT: 30.1; LR: 30.1 & 47.80 & 89.90 & 85.82 & 20,635 & 3.25 & 6.51 & - \\
\hline $\begin{array}{l}\text { Hwang et al., } \\
2007\end{array}$ & South Korea & $1997-2005$ & 3 & 4 & Enhanced & & 52.89 & 85.71 & 100.00 & - & - & - & - \\
\hline Jiang et al., 2014 & China & 2007-2012 & 34 & 33 & Enhanced & $\begin{array}{c}\text { LT: } 43.5 \text { (mean); LR: } \\
31.2 \text { (mean) }\end{array}$ & 47.69 & 85.07 & 98.51 & - & 2.50 & 34.33 & - \\
\hline $\begin{array}{l}\text { Koniaris et al., } \\
2011\end{array}$ & USA & 1999-2009 & 33 & 205 & - & & - & - & - & - & - & - & - \\
\hline $\begin{array}{l}\text { Krenzien et al., } \\
2018\end{array}$ & Germany & 1989-2011 & 214 & 59 & Non-enhanced & & 56.93 & 77.76 & 100.00 & - & - & 42.21 & - \\
\hline $\begin{array}{l}\text { Kuroda et al., } \\
2011\end{array}$ & Japan & 1986-2008 & 21 & 48 & Non-enhanced & LT: 40.9; LR: 34.2 & - & - & - & - & - & - & - \\
\hline Lee et al., 2010 & South Korea & $1997-2007$ & 48 & 82 & - & $\begin{array}{c}\text { LT: } 49.1 \text { (mean); LR: } \\
66.5 \text { (mean) }\end{array}$ & - & - & - & - & - & - & - \\
\hline Li et al., 2017 & China & $2007-2013$ & 67 & 137 & - & & - & - & - & - & - & - & - \\
\hline Li et al., 2014 & China & $2007-2012$ & 39 & 243 & Enhanced & & 49.55 & 87.23 & - & - & 3.25 & 19.86 & 100 \\
\hline $\begin{array}{l}\text { Llovet et al., } \\
1999\end{array}$ & Spain & 1989-1997 & 87 & 77 & Non-enhanced & LT: 26; LR: 32 & 57.87 & 68.90 & 100.00 & - & 2.85 & 20.12 & - \\
\hline $\begin{array}{l}\text { Meyerovich et } \\
\text { al., } 2019\end{array}$ & Israel & $2007-2016$ & 57 & 30 & Enhanced & LT: 23.3; LR: 27.7 & 61.95 & 69.03 & 100.00 & 212.56 & 3.21 & 17.50 & - \\
\hline $\begin{array}{l}\text { Michelakos et } \\
\text { al., } 2019\end{array}$ & USA & $1992-2015$ & 89 & 95 & - & & 61.45 & 81.52 & 100.00 & 20.68 & 3.35 & - & - \\
\hline $\begin{array}{l}\text { Moon et al., } \\
2007\end{array}$ & South Korea & 1995-2005 & 17 & 100 & Enhanced & LT: 22; LR: 77 & 52.74 & 80.34 & 100.00 & - & 2.33 & 7.69 & 100 \\
\hline Park et al., 2017 & South Korea & 1999-2010 & 137 & 199 & Enhanced & $\begin{array}{c}\text { LT: } 37.8 \text { (mean); LR: } \\
28.7 \text { (mean) }\end{array}$ & 54.28 & 76.49 & 100.00 & 905.96 & 2.63 & 20.24 & - \\
\hline $\begin{array}{l}\text { Peters et al., } \\
2017\end{array}$ & USA & 2004-2012 & 1,445 & 2,121 & - & & - & - & - & - & - & - & - \\
\hline $\begin{array}{l}\text { Sapisochin et al., } \\
2013\end{array}$ & Spain & $1991-2007$ & 119 & 95 & Non-enhanced & LT: 63.6; LR: 63.6 & 62.22 & 69.55 & 100.00 & 184.36 & 3.00 & 15.22 & 100 \\
\hline Shah et al., 2007 & Canada & 1995-2005 & 140 & 121 & - & LT: 35; LR: 35 & 51.45 & 50.29 & 100.00 & & 3.52 & - & - \\
\hline $\begin{array}{l}\text { Sogawa et al., } \\
2013\end{array}$ & USA & $2002-2007$ & 75 & 56 & Enhanced & LT: 30.1; LR: 46.6 & 58.81 & 77.10 & 100.00 & $1,477.70$ & 2.64 & 49.41 & - \\
\hline $\begin{array}{l}\text { Sotiropoulos et } \\
\text { al., } 2009\end{array}$ & Germany & 1998-2007 & 26 & 61 & - & & - & - & - & - & 6.78 & - & - \\
\hline Sung et al., 2017 & South Korea & 1997-2006 & 67 & 89 & - & & 52.91 & 80.13 & 74.36 & & 2.46 & 13.46 & 100 \\
\hline Wu et al., 2020 & China & 2004-2015 & 1,480 & 1,538 & - & & - & - & - & - & - & - & 100 \\
\hline Yang et al., 2017 & China & 2004-2013 & 258 & 288 & - & & 59.64 & 74.95 & - & - & - & - & 100 \\
\hline Yokoi et al., 2006 & Japan & 1990-2003 & 11 & 94 & - & & - & - & - & - & - & - & - \\
\hline Zhou et al., 2010 & China & 2003-2007 & 89 & 1,018 & Enhanced & LT: 31; LR: 31 & 51.34 & 82.93 & 100.00 & - & - & 25.21 & - \\
\hline
\end{tabular}

LT, liver transplant, LR, liver resection; AFP, alpha-fetoprotein. 
Table S2 NOS

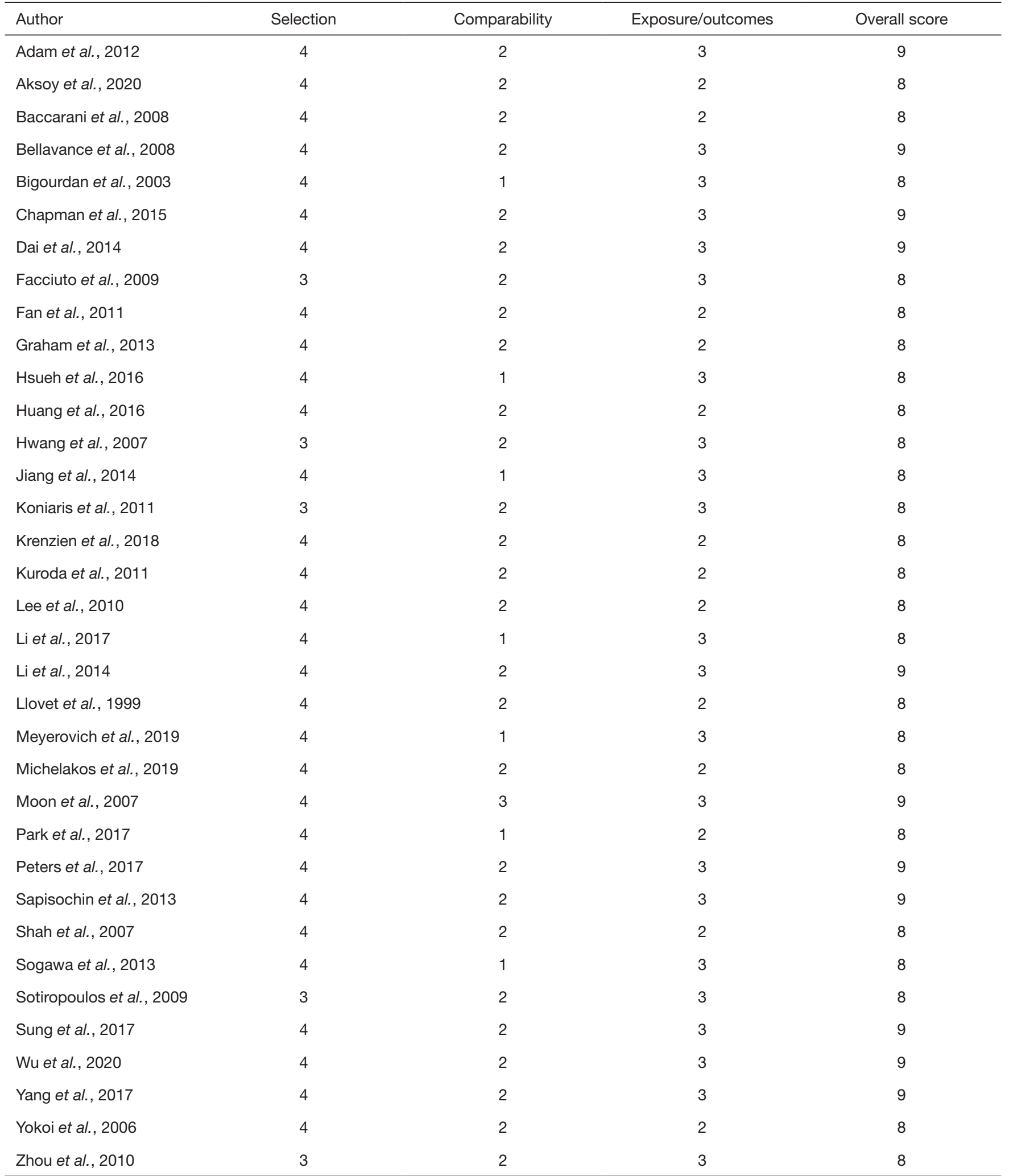

NOS, Newcastle-Ottawa Scale quality assessment. 


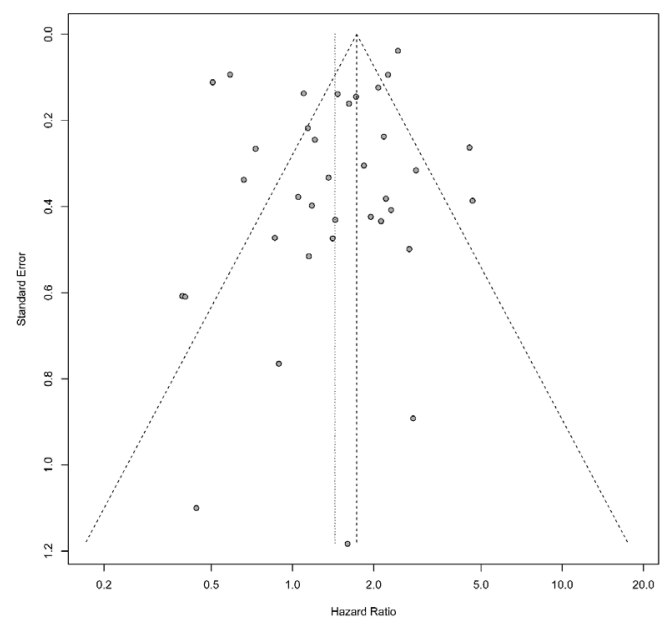

Figure S1 Funnel plot for OS. OS, overall survival.

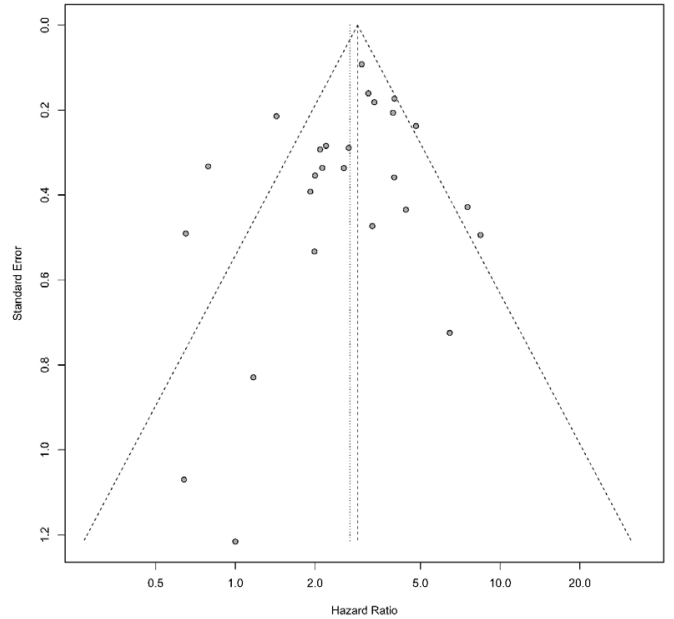

Figure S2 Funnel plot for DFS. DFS, disease-free survival.
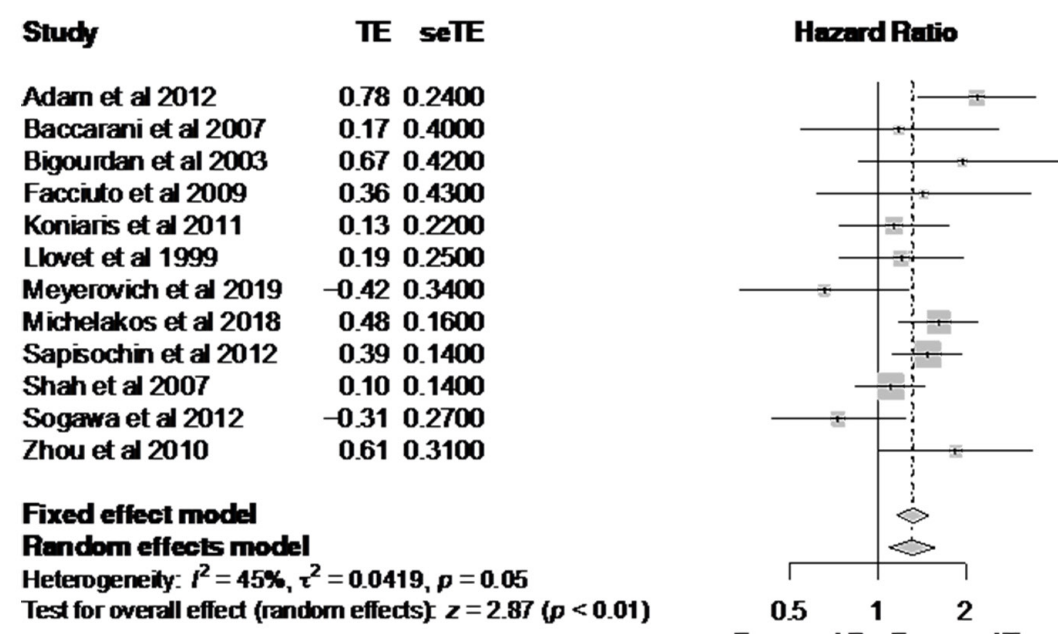

HA $\quad 95 \%$ C Weight Weight

Favours LR Favours LT

Figure S3 Forest plot for OS among patients who underwent LR versus LT for HCC, ITT analysis studies only. HR, hazard ratio; CI, confidence interval; OS, overall survival; LR, liver resection; LT, liver transplantation; HCC, hepatocellular carcinoma; ITT, intention-totreat. 


\begin{tabular}{lr} 
Study & TE seTE \\
\hline & \\
\hline Adarn et al 2012 & 1.3702100 \\
Baccarani et al 2007 & 0.760 .3400 \\
Bigourdan et al 2003 & 0.160 .8300 \\
Koniaris et al 2011 & 0.3602100 \\
Meyerovich et al 2019 & -0.240 .3300 \\
Michelakos et al 2018 & 2.020 .4300 \\
Zhou et al 2010 & 0.7902800 \\
& \\
Fixed effect model & \\
Random effects model \\
Heterogeneity. $t^{2}=80 \%, \tau^{2}=0.3679, p<0.01$ \\
Test for overall effect (random effects) $z=290(p<0.01)$
\end{tabular}

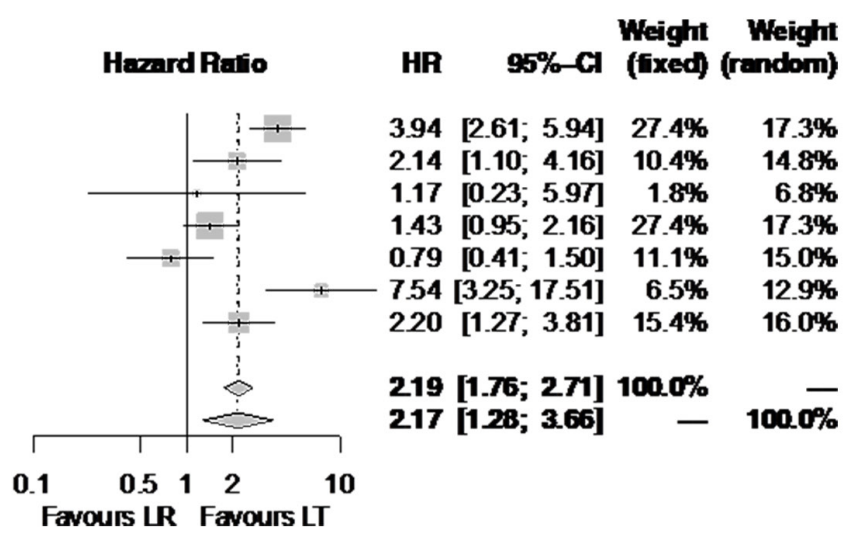

Figure S4 Forest plot for DFS among patients who underwent LR versus LT for HCC, ITT analysis studies only. HR, hazard ratio; CI, confidence interval; DFS, disease-free survival; LR, liver resection; LT, liver transplantation; HCC, hepatocellular carcinoma; ITT, intention-to-treat. 